\title{
Zoneamento da fragilidade ambiental de ecossistemas naturais e antropizados por meio de avaliação multicritério
}

\section{Luciano Cavalcante de Jesus FRANÇA ${ }^{1 *}$, Danielle Piuzana MUCIDA², Marcelino Santos de MORAIS ${ }^{3}$, Humberto CATUZZO ${ }^{3}$, João Luís Ramalho $\mathrm{ABEGÃO}^{4}$, Israel Marinho PEREIRA ${ }^{2}$}

\author{
${ }^{1}$ Programa de Pós-Graduação em Engenharia Florestal, Universidade Federal de Lavras, Lavras, MG, Brasil. \\ ${ }^{2}$ Programa de Pós-Graduação em Engenharia Florestal, Universidade Federal dos Vales do Jequitinhonha e Mucuri, \\ Diamantina, MG, Brasil. \\ ${ }^{3}$ Departamento de Geografia, Universidade Federal dos Vales do Jequitinhonha e Mucuri, Diamantina, MG, Brasil. \\ ${ }^{4}$ Programa Doutoral em Alterações Climáticas e Políticas de Desenvolvimento Sustentável, Universidade de Lisboa, Lisboa \\ Portugal. \\ *E-mail: lucianodejesus@florestal.eng.br
}

Recebido em setembro/2018; Aceito em março/2019.

\begin{abstract}
RESUMO: A fragmentação de ecossistemas é uma das implicações do processo de uso e ocupação antrópico da terra, especialmente em paisagens alteradas por cultivos agrícolas ou florestais. Nesse contexto, o presente estudo objetivou determinar a fragilidade ambiental do município de Capelinha, Vale do Jequitinhonha, Minas Gerais, Brasil, utilizando-se da técnica de avaliação por múltiplos critérios por meio do software ArcGIS ${ }^{\mathrm{TM}} 10.3 .1$ e do método de hierarquização para tomadas de decisões Analytic Hierarchy Process (AHP). Após gerados os mapas de classes de declividade, solos, hierarquia fluvial, domínios geológicos, pluviosidade e uso atual da terra, foram atribuídos pesos de fragilidade para cada um dos fatores, estabelecidos com base em metodologia clássica, sendo eles: (I) Baixa, (II) Levemente Baixa, (II) Média, (IV) Alta e (V) Extremamente Alta. A partir da Combinação Linear Ponderada e álgebra de mapas, foram geradas as cartas de fragilidade ambiental potencial e emergente. A metodologia mostrou-se adequada, apoiada no método AHP na definição dos sítios de maior e menor fragilidade. Os mapas aqui gerados, embora sejam uma generalização da possível condição de fragilidade ambiental da área de estudo e, não da realidade em si, todavia, poderão apoiar estratégias de uso da terra para a restauração ambiental e fornecer introspecções para ordenamento territorial.
\end{abstract}

Palavras-chave: manejo de ecossistemas; planejamento ambiental; restauração ambiental; álgebra de mapas; sistema de informações geográficas.

\section{Zoning environmental fragility of natural and anthropized ecosystems by multicriteria evaluation}

\begin{abstract}
Fragmentation of ecosystems is one of the implications of the land use and the occupation process, especially in landscapes altered by agricultural or forestry crops. In this context, the present study aimed to determine the environmental fragility of the Capelinha municipality, Jequitinhonha Valley, Minas Gerais, Brazil, by a multiple criteria evaluation technique using ArcGIS TM software 10.3.1 and the Analytic Hierarchy Process (AHP). After generating maps of slope classes, soils, river hierarchy, geological domains, rainfall and current land use, weights of fragility were assigned to each of the factors, established based on classical methodology, those being: (I) (II) Slightly Low, (II) Medium, (IV) High and (V) Extremely High. Through Weighted Linear Combination and map algebra, maps of potential and emergent environmental fragility were generated. The methodology was commensurate to the task, which was supported by the AHP method and observation of the characteristics occurrences of the variables that corroborated with the sites of greater or lesser fragility. The maps generated here may support and enhance land use strategies for environmental restoration, as well as providing insights on spatial planning and management of environmental services.
\end{abstract}

Keywords: ecosystem management; environmental planning; environmental restoration; map algebra; geographic information system.

\section{INTRODUÇÃO}

Os impactos ambientais na alteração de ecossistemas naturais tem sido motivo frequente de preocupação pública, em consequência aos efeitos à biodiversidade e fragmentação florestal, que alteram além dos aspectos ecodinâmicos, fatores econômicos e sociais em todas as partes do mundo.

O habitat e a fragmentação resultantes principalmente do aumento dos impactos humanos relacionados ao uso da terra representam ameaças consideráveis à biodiversidade (XIE et al., 2017). As mudanças no uso da terra estão relacionadas à urbanização, economia e tecnologia, influenciando a gestão dos recursos naturais e os processos ecossistêmicos (LOPES et al., 2018). É, nesse contexto, que insere-se o conceito de fragilidade ambiental, que diz respeito à vulnerabilidade de ambientes e relaciona-se a fatores de desequilíbrio, tanto de ordem natural, expressa pela própria dinâmica do ambiente, como em situações de elevadas declividades e altas susceptibilidades erosivas dos solos, quanto antropogênica, 
associada ao exemplo do mau uso do terreno e de intervenções em regimes fluviais (TAMANINI, 2008).

Portanto, ao conceito de fragilidade ambiental, devem-se destacar duas propostas distintas de análise: fragilidade potencial e fragilidade emergente. A fragilidade potencial é definida como sendo a susceptibilidade natural de um ambiente em função de suas características biofísicas da paisagem, como declividade do terreno, tipo de solo, arcabouço geológico, hierarquia fluvial e pluviosidade. Já a fragilidade emergente, além dos aspectos biofísicos, contempla, também, os graus de proteção da terra, tais como os diferentes tipos de uso e cobertura da terra.

Modelos de fragilidade ambiental são importantes ferramentas de decisão no âmbito político, uma vez que ajudam a quantificar a sensibilidade ambiental e entender o relacionamento entre as atividades humanas e a qualidade ambiental (MANFRÉ et al., 2013). Destaca-se, além disso, que conhecer áreas menos ou mais vulneráveis a processos de degradação é de suma importância para as instituições governamentais e de pesquisa no campo da restauração de áreas degradadas.

A proposta metodológica de Ross (1994) estabelece os princípios da fragilidade ambiental e, baseia-se na aplicação das concepções de ecodinâmica e ecossistema, elaboradas por Tricart (1977), para uso em projetos de planejamento ambiental. Por sua vez, a metodologia para determinação da fragilidade ambiental com base nas classes de declividade proposta por Ross (1994) é a mais utilizada no meio científico. Todavia, nota-se que a maioria dos autores utiliza essa proposta com determinadas adaptações, visando obter resultados mais aproximados para a realidade de cada ambiente.
Dessa forma, compreende-se que a identificação de locais com menor e maior grau de fragilidade trata-se de importante produto da modelagem geoespacial. O recurso da modelagem é um subsídio tecnológico que permite a estimativa de fenômenos pretéritos, até mesmo de possíveis cenários futuros (MELO et al., 2016), além de estruturação de modelos de risco de degradação ambiental (MELO et al., 2018). Logo, a determinação de áreas com diferentes graus de vulnerabilidade a degradação ambiental, pode auxiliar nas políticas públicas municipais, estaduais e/ou federais sobre avaliação ambiental estratégica, além de fornecer subsídio a investimentos privados de implantação agrícola, reflorestamentos comerciais, mineração, dentre outros.

Diante do exposto, este estudo tem como objetivo determinar a fragilidade ambiental potencial e emergente do município de Capelinha, na mesorregião do Vale do Jequitinhonha, Minas Gerais, Brasil, a partir de uma adaptação metodológica de Ross (1994), com acréscimo de novas variáveis ambientais.

\section{MATERIAL E MÉTODOS}

2.1. Área de estudo

A área de estudo compreende o município de Capelinha, localizado no Vale do Jequitinhonha, Minas Gerais, Brasil (Figura 1).

O Vale do Jequitinhonha abrange grande parte do nordeste do estado de Minas Gerais (11,3\% do território do estado) e pequeno setor do sudeste da Bahia (0,8\%) (IBGE, 1997). Capelinha encontra-se no território do Alto Jequitinhonha, e seu município conta com área total de $965,9 \mathrm{~km}^{2}$. A sede municipal encontra-se a $718 \mathrm{~m}$ de altitude e dista $480 \mathrm{~km}$ de Belo Horizonte, capital do estado.
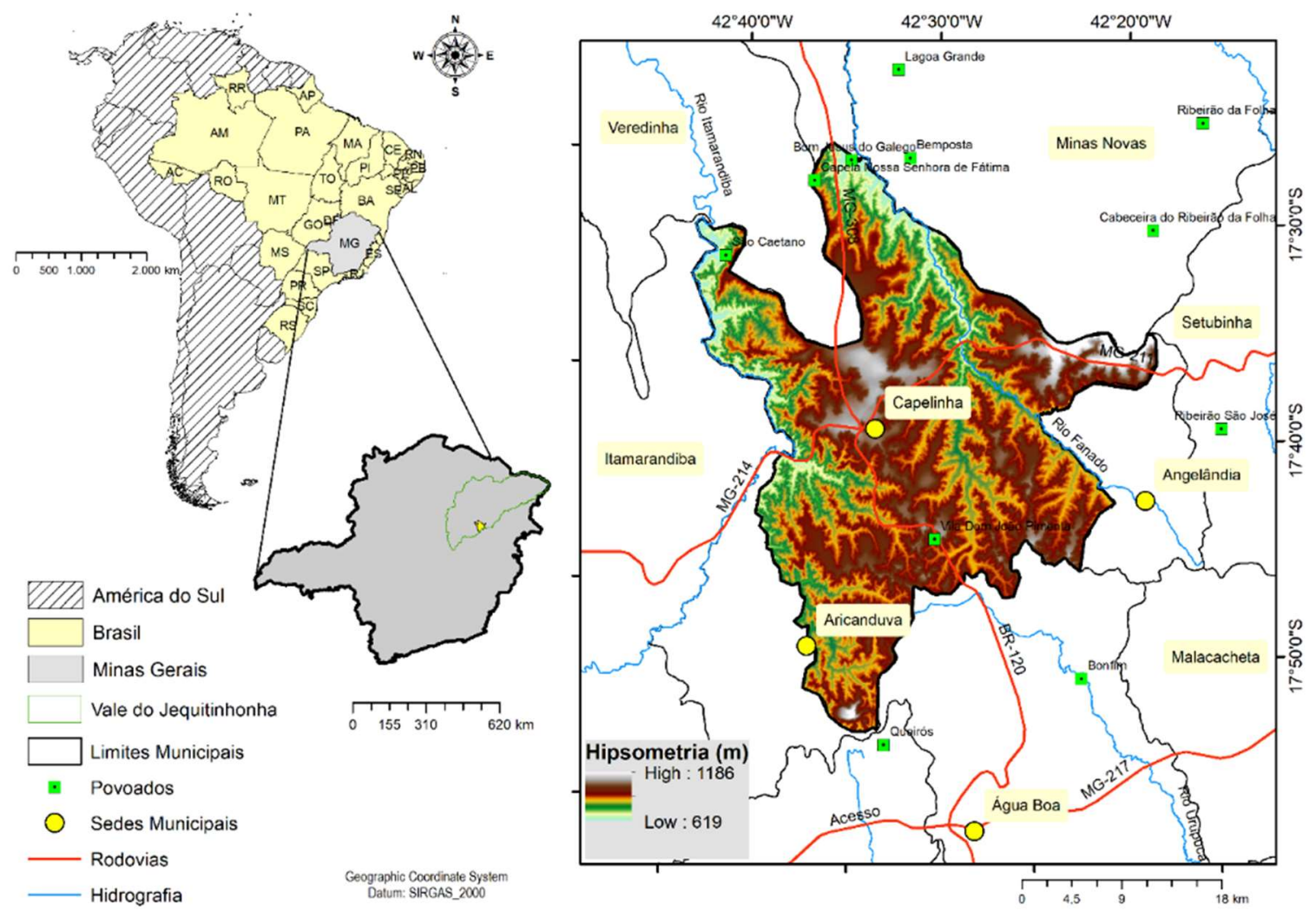

Figura 1. Localização do município de Capelinha no contexto do estado de Minas Gerais, Brasil.

Figure 1. Location of the Capelinha municipality, Minas Gerais state, Brazil. 
O município encontra-se em Áreas de Contato Cerrado/Floresta Estacional. Sua porção centro-norte caracteriza-se por chapadas e relevos tabulares que posicionam-se em altitudes que variam de 700 a $1.000 \mathrm{~m}$, com predominância do domínio Cerrado. Entretanto, atualmente, essas áreas caracterizam-se pela ocorrência generalizada de reflorestamentos de espécies exóticas (Eucalyptus spp). Na porção leste e sul do município ocorrem as florestas estacionais, em transição com vegetação característica da Mata Atlântica. Quanto a áreas de cultivo, Capelinha possui ainda, de forma significativa, a cultura do café (Coffea spp.) (IBGE, 1997).

Os rios Fanado e Itamarandiba são os principais recursos hídricos do município. Estes e seus afluentes marcam os menores valores altimétricos no município (Figura 1).

\subsection{Planos de informações geográficas}

Foram utilizados planos de informações geográficas para a determinação da fragilidade ambiental potencial e emergente da área de estudo, por meio da sobreposição de informações para a geração dos mapas finais com as distintas classes de fragilidade. Todas as etapas da presente metodologia foram realizadas com auxílio do software ArcGIS 10.3.1 ${ }^{\mathrm{TM}}$ (ESRI, 2013).

Para a geração de um Modelo Digital de Elevação Hidrologicamente Consistente (MDHEC), utilizaram-se imagens raster da base SRTM do Modelo Digital de Elevação (MDE). A fonte primária de dados apresenta aproximadamente 90 metros de resolução espacial originária da missão de mapeamento do relevo terrestre SRTM (Shuttle Radar Topography Mission), desenvolvido pela NASA (National Aeronautics and Space Administration) e NGA (National Geospatial-Intelligence Agency) (MIRANDA, 2005).

O Modelo Digital de Elevação gerado a partir de dados do SRTM, por sua vez, geralmente apresenta depressões espúrias no relevo. Nos dados SRTM, a presença de irregularidades é natural no relevo, sendo mais frequentes em áreas cuja inclinação da superfície seja maior que 20 graus, pois há o sombreamento ocasionado pelo radar (LUEDELING et al., 2007). Para correção dessas falhas, utilizou-se o comando Fill Sinks da plataforma SIG, suavizando a consistência no mapa do MDE (OLIVEIRA et al., 2010).

O Plano de informação de declividade do terreno foi elaborado a partir do Modelo Digital de Elevação, por meio do módulo Spatial Analyst Tools > Surface > Slope, da plataforma de SIG. As classes de declividade seguiram recomendação da Embrapa (1979), que divide terrenos em categorias: plano (0-3\%), suave ondulado (3-8 \%), ondulado (8-20\%), forte ondulado (20-45\%) e forte montanhoso ou escarpado $(45-75 \%)$.

O Plano de informação de hierarquia fluvial foi fundamentado no Modelo Digital de Elevação. Adotou-se o método do sistema de classificação introduzido por Strahler (1952), no qual a identificação inicia-se com cursos de $1^{\mathrm{a}}$ ordem, que são aqueles que não recebem nenhum afluente. A partir da confluência de dois cursos de $1^{\mathrm{a}}$ ordem, forma-se um segmento de $2^{\mathrm{a}}$ ordem e, assim sucessivamente. Quando dois segmentos de ordens diferentes juntam-se, prevalece a maior ordem.

Para o Plano de informação classes de solo foi utilizado dados do Mapa de Solos de Minas Gerais (FEAM, 2010) e quanto às classes dos solos, foi aplicada a nomenclatura da
Embrapa (2011). Adotou-se a classificação de Ross (1994), que hierarquiza em cinco categorias para classes de fragilidade nas quais são considerados: textura, estrutura, plasticidade, grau de coesão das partículas e profundidade dos horizontes superficiais e subsuperficiais.

A base de dados para a Pluviosidade foi extraída do Atlas Pluviométrico do Brasil, gerado a partir dos dados das Estações Pluviométricas existentes na bacia do rio Jequitinhonha (CPRM, 2016). Os dados são de uma série histórica do período entre 1977 e 2006 (período base) na forma de Isoetas de Precipitações Médias Anuais disponibilizado em arquivo shapefile. Realizou-se a espacialização dos dados climáticos por meio da conversão de linhas de isoetas em pontos de referência pluviométrica, que posteriormente foram espacializados pelo método Inverse Distance Weighted IDW.

O Plano de informação de unidades geológico-ambientais recebeu atribuições de valores de fragilidade considerando o grau de coesão das rochas e de susceptibilidade ao intemperismo físico e químico de acordo com a carta de vulnerabilidade natural à perda de solo (QUARTAROLI et al., 2013) e com valores de vulnerabilidades recomendados por Crepani et al. (2001).

Por fim, para o Plano de informação uso e ocupação do terreno, foram utilizadas imagens do satélite RapidEye, com cenas mosaicadas referentes ao ano de 2015. As imagens são adquiridas já ortorretificadas. Executou-se o método de mapeamento do uso e ocupação do terreno por meio da técnica de Classificação Supervisionada com o classificador MaxVer (Máxima Verossimilhança). As classes foram divididas em 5 (cinco): Florestas Plantadas, Cobertura Florestal Nativa, Pastagem Natural ou Artificial, Mosaico de Vegetação Campestre/Áreas Agrícolas, Urbanização/Edificações e Solo Exposto. O processamento das imagens foi executado no software ArcGIS 10.3.1 ${ }^{\mathrm{TM}}$ (ESRI, 2013).

\subsection{Método Analytic Hierarchy Process (AHP)}

Pautado na estrutura do método AHP, elaborou-se uma matriz matemática de comparação pareada dos múltiplos critérios considerados no estudo, resultando nos pesos atribuídos a cada camada. Em seguida, procedeu-se com a média ponderada de todas as camadas com base nos resultados da matriz que apresentou os fatores por grau de importância, adaptado de Saaty (2008). A resolução da matriz tomou como base uma escala de comparação de critérios, conforme apresentado na Tabela 1.

Segundo Saaty (2008), o processo analítico hierárquico (AHP) deve atender três pressupostos: Reciprocidade: $\mathrm{Se} \mathrm{a}_{\mathrm{ij}}=$ $\mathrm{x}$, então $\mathrm{a}_{\mathrm{ji}}=1 / \mathrm{x}$; Homogeneidade: Se os elementos $i$ e $j$ são considerados igualmente importantes, então, aij = aji $=1$, além disso, $\mathrm{a}_{\mathrm{i}}=1$ para todo $i$; e Consistência: Razão de Consistência (RC) e Índice de Consistência (IC).

\subsection{Consistência da matriz AHP}

A consistência da matriz de comparação pareada AHP permite analisar, determinar e decidir os diversos critérios que influem na tomada de decisão e, consequentemente, gerar informações que auxiliem o decisor a eleger a melhor das alternativas propostas, com base nos critérios analisados. Mais do que determinar a decisão correta, o método permite justificar a escolha de forma consistente e coerente (SANTOS; CRUZ, 2013). 
Tabela 1. Escala referente à importância relativa a partir da comparação de critérios, adaptada de Saaty (2008).

Table 1. Comparison scale with the previous comparison, adapted from Saaty (2008).

\begin{tabular}{ccl}
\hline Pesos & $\begin{array}{c}\text { Escala de } \\
\text { Importância }\end{array}$ & \multicolumn{1}{c}{ Descrição } \\
\hline 1 & $\begin{array}{c}\text { Importância } \\
\text { igual a }\end{array}$ & $\begin{array}{l}\text { Os dois critérios contribuem igualmente } \\
\text { para o objetivo. }\end{array}$ \\
\hline 2 & $\begin{array}{c}\text { Importância } \\
\text { moderada } \\
\text { maior }\end{array}$ & $\begin{array}{l}\text { A análise, a experiência e o julgamento } \\
\text { favorecem levemente uma atividade em } \\
\text { relação à outra. }\end{array}$ \\
\hline 3 & $\begin{array}{c}\text { Importância } \\
\text { extremament } \\
\text { e maior }\end{array}$ & $\begin{array}{l}\text { Um dos critérios é absolutamente } \\
\text { predominante sobre o outro; a evidência } \\
\text { favorece uma atividade em relação à } \\
\text { outra com o mais alto grau de } \\
\text { importância. }\end{array}$ \\
0,5 & $\begin{array}{c}\text { Importância } \\
\text { moderada } \\
\text { menor }\end{array}$ & $\begin{array}{l}\text { A análise, a experiência e o julgamento } \\
\text { favorecem levemente uma atividade em } \\
\text { relação à outra. }\end{array}$ \\
\hline & $\begin{array}{c}\text { Importância } \\
\text { extremament } \\
\text { e menor }\end{array}$ & $\begin{array}{l}\text { Um dos critérios é absolutamente } \\
\text { predominante sobre o outro; a evidência } \\
\text { favorece uma atividade em relação à } \\
\text { outra com o menor grau de importância. }\end{array}$ \\
\hline
\end{tabular}

Contudo, é necessário verificar a inconsistência dos dados. A verificação visa constatar se os decisores foram consistentes nas suas opiniões para a tomada de decisão. Assim, o cálculo do Índice de Consistência (SAATY, 2005) é dado pela equação:

$$
\text { I. } \mathrm{C}=\frac{\lambda \operatorname{Max}-n}{n-1}
$$

em que: $\mathrm{IC}=$ Índice de Consistência; $\mathrm{n}=$ Número de critérios avaliados; $\lambda \mathrm{Max}=$ Número principal de Eigen.

O autovetor, ou vetor principal de Eigen ( $\lambda$ Max), é obtido calculando-se o somatório do produto de cada elemento da matriz de comparação com o vetor de prioridade (Eigen) de cada critério, dividindo-se o resultado dessa expressão pelo vetor de prioridade do qual se calcula a média aritmética (SANTOS; CRUZ, 2013).

Dessa forma, é necessário verificar se o valor encontrado do Índice de Consistência (IC) é adequado. Para tanto, Saaty (2005) propôs uma Relação, ou Razão, de Consistência (RC), que é determinada pela razão entre o valor do IC e o índice de consistência aleatória, ou Índice Randômico (IR), que varia com o tamanho $n$ da amostra. A relação é demonstrada pela expressão (SAATY, 2005):

$$
R \cdot \mathrm{C}=\frac{\mathrm{IC}}{\mathrm{IR}}
$$

em que: IR é um valor constante e depende da dimensão da matriz que se está comparando, ou seja, do número de critérios avaliados, conforme a Tabela 2.

Tabela 2. Valores de IR (Índice Randômico) para matrizes de diferentes tamanhos. Retirado de Saaty (2005).

Table 2. IR values (Random Index) for matrices of different sizes. Retrieved from Saaty (2005).

\begin{tabular}{cc}
\hline Dimensão da matriz $(\mathrm{n})$ & Valor de I.R \\
\hline 1 & 0 \\
\hline 2 & 0 \\
\hline 3 & 0,58 \\
\hline 4 & 0,9 \\
\hline 5 & 1,12 \\
\hline 6 & 1,24 \\
\hline 7 & 1,32 \\
\hline 8 & 1,41 \\
\hline 9 & 1,45 \\
\hline 10 & 1,49 \\
\hline
\end{tabular}

O grau de consistência é satisfatório quando os valores de RC forem inferiores a 0,1 (SAATY. 2005). Quando encontrados valores de RC superiores a $0,1(10 \%)$, o autor recomenda reavaliar os dados levantados junto aos especialistas, verificando-se possíveis equívocos ou erros durante o processo de levantamento.

\subsection{Mapas da Fragilidade Ambiental Potencial e Emergente (FAP e FAE)}

Para a determinação da fragilidade ambiental potencial (FAP), neste estudo, foram utilizados os seguintes critérios: declividade do terreno, classes de solo, pluviosidade, domínios geológicos e hierarquia fluvial. Para cada um desses parâmetros foram estabelecidas classes de fragilidade, conforme o estudo individual de suas características, isto é, foram atribuídos pesos de 1 a 5 por variável, representando nomeadamente as categorias: 1 (Baixa), 2 (Levemente Baixa), 3 (Média), 4 (Alta) e 5 (Extremamente Alta), tal como enquadrados nas caracterização e descrição apresentadas na Tabela 3. Assim como o mapa final de FAP, que apresenta a mesma categorização após a álgebra dos mapas referentes aos múltiplos critérios.

Tabela 3. Classes de fragilidade e seus respectivos pesos e descrições (ROSS, 1994).

Table 3. Fragility classes and their respective weights and descriptions (ROSS, 1994).

\begin{tabular}{c|c|l}
\hline Classes & Pesos & \multicolumn{1}{c}{ Descrição } \\
\hline Baixa & 1 & Caracteriza áreas por condição de equilíbrio e estabilidade das características físico-naturais de um ecossistema. \\
\hline $\begin{array}{c}\text { Levemente } \\
\text { Baixa }\end{array}$ & 2 & Condições físicas de estabilidade do ambiente, com ao menos uma característica que não se inclui na classe anterior. \\
\hline Média & 3 & $\begin{array}{l}\text { Ambiente com caracteres de fragilidade em transição das classes mais baixas para as classes altas. Trata-se da } \\
\text { categoria de alerta para os riscos ambientais naturais sob a qual determinado ambiente está sujeito. Áreas que } \\
\text { merecem maior atenção para conservação, proteção e técnicas de manejo adequadas do solo, dos recursos hídricos } \\
\text { e do ordenamento do território. }\end{array}$ \\
\hline Alta & 4 & $\begin{array}{l}\text { Caracteriza áreas com alta susceptibilidade a processos de degradação ambiental (física, química e biológica), } \\
\text { devido à maior acentuação de parâmetros e critérios analisados. Merecem muita atenção do ponto de vista } \\
\text { ambiental. São as áreas com restrições as atividades antrópicas de ocupação e uso, devido à elevada instabilidade } \\
\text { das características naturais do ambiente. }\end{array}$ \\
\hline $\begin{array}{c}\text { Extremam } \\
\text { ente Alta }\end{array}$ & 5 & $\begin{array}{l}\text { Áreas com intensa sensibilidade ambiental, inaptas a qualquer tipo de atividade antrópica que provoque alterações } \\
\text { no ambiente. Reúnem as mais frágeis combinações de características físicas-naturais favoráveis a tornarem-nas } \\
\text { áreas degradadas. São de extrema susceptibilidade a erosões e voçorocamentos. }\end{array}$ \\
\hline
\end{tabular}

Nativa, Sinop, v. 7, n. 5, p. 589-599, set./out. 2019. 
A FAP, diferente da fragilidade ambiental emergente (FAE), representa fatores intrínsecos à paisagem, enquanto a emergente considera ainda a cobertura da terra e intervenções humanas (VALLE et al., 2016). Para a geração do mapa de FAE, executou-se a álgebra da FAP com a carta de uso e ocupação do terreno. $\mathrm{O}$ estudo dessas variáveis possibilita a definição das classes de fragilidade naturalmente potenciais à erosão e movimentação dos solos, que, quando sujeitos as ações antropogênicas, poderão apresentar-se em condições de instabilidade ambiental.

Aplicou-se a seguinte equação para cálculo de soma algébrica $\left(\sum F\right)$ dos PI para geração da carta de FAP:

$$
F A P=\sum(F n * X n)
$$

em que: $\mathrm{FAP}=$ Fragilidade Ambiental Potencial; $\mathrm{F}_{\mathrm{n}}=$ Fragilidade dos $n$ parâmetros; $\mathrm{X}_{\mathrm{n}}=$ Pesos estatísticos dos $n$ parâmetros.

A sobreposição de FAP com a informação de uso e ocupação do terreno, consistiu na geração do mapa de FAE, conforme a equação abaixo:

$$
F A E=\{(F A P+(F . \text { uso } * X n)\}
$$

em que: $\mathrm{FAE}=$ Fragilidade Ambiental Emergente; $\mathrm{FAP}=$ Fragilidade Ambiental Potencial; $F_{U S O}=$ Fragilidade quanto ao Uso e Ocupação do Terreno; $X_{n}=$ Pesos estatístico do parâmetro.

\section{RESULTADOS}

Confeccionaram-se as cartas referentes a declividade do terreno, classes de solo, domínios geológicos, pluviosidade, hierarquia fluvial e uso e ocupação do terreno, que, aqui, compõem o Plano de Informações Multicritério. Realizou-se a reclassificação de cada variável em uma mesma escala de valor, que variou de Baixa a Extremamente Alta. Os pesos atribuídos aos seis fatores considerados no estudo são apresentados na Tabela

Para as classes de solo, atribuiu-se o peso 1 (um) para áreas com solos menos susceptíveis a processos erosivos e 4 (quatro) para aqueles com maior susceptibilidade, assim como, características que enquadram cada tipo de solo em uma hierarquia de menor a maior fragilidade (Figura 2A).

Para Declividade do Terreno, atribuíram-se os pesos em ordem crescente de acordo com a sua variação, de plano a montanhoso (Tabela 4). Observa-se alta predominância de terrenos na classe forte ondulado, conforme observado na Figura 2C.

Em termos de Domínios Geológicos, a contribuição da Geologia para a análise e definição da categoria morfodinâmica da unidade de paisagem natural compreende as informações relativas à história da evolução geológica e as informações relativas ao grau de coesão das rochas que a compõem (QUARTAROLI et al., 2013).

A partir de critérios de Ross (1994), constata-se a distribuição de domínios de Sequências Vulcanossedimentares Proterozoicas dobradas metaformizadas de baixo e alto grau, classificados por uma fragilidade Levemente Baixa; domínio das Coberturas Cenozoicas Detrito-Lateríticas, com Extremamente Alta fragilidade; e domínio dos Complexos Gnaisse-Migmatítico e Granulitos, de fragilidade Levemente Baixa (Tabela 4).

No que concerne aos Dados Pluviométricos, o município de Capelinha apresenta isoietas de precipitação média anual que variam entre $1.043,16 \mathrm{~mm}$ a $1.129,42 \mathrm{~mm}$, considerandose a série histórica de 30 anos utilizada neste estudo, e também a condição de que são dados mais generalizados. Contudo, por se tratar de um município de pequena extensão territorial, caracteriza-se pela distribuição anual de chuvas bastante uniforme. O Mapa de Precipitação Pluviométrica de Capelinha é apresentado na Figura 2D.

Em termos de Hierarquia Fluvial, verificaram-se, para o município de Capelinha, cursos d'agua de até $6^{\mathrm{a}}$ ordem, de acordo com a classificação de Strahler (1952). O município apresentou maior distribuição espacial para leitos fluviais de $1^{\mathrm{a}}$ ordem, aqueles que se estendem desde a nascente até a confluência. O mapa com a classificação da hierarquia fluvial da bacia do município de Capelinha é apresentado na Figura $2 \mathrm{E}$, e seus pesos quanto à fragilidade ambiental encontram-se na Tabela 4

Tabela 4. Classes de fragilidade atribuídas aos fatores considerados para Capelinha, Minas Gerais, Brasil.

\begin{tabular}{|c|c|c|c|c|c|c|}
\hline Pesos & $\begin{array}{c}\text { Declividade } \\
\text { do terreno }\end{array}$ & Classes de Solo & $\begin{array}{c}\text { Domínios } \\
\text { Geológicos }\end{array}$ & $\begin{array}{c}\text { Pluviosidade } \\
(\mathrm{mm})\end{array}$ & $\begin{array}{c}\text { Hierarquia } \\
\text { Fluvial } \\
\end{array}$ & $\begin{array}{l}\text { Uso e Ocupação da Terra } \\
\text { (Grau de Proteção) }\end{array}$ \\
\hline 1 & $\begin{array}{l}\text { Plano } \\
(0-3 \%)\end{array}$ & $\begin{array}{l}\text { LatossoloVermelho/ } \\
\text { Vermelho Amarelo }\end{array}$ & --- & $\begin{array}{c}1.043,16- \\
1.086,29\end{array}$ & $\begin{array}{l}5^{\mathrm{a}} \text { Ordem/ } \\
6^{\mathrm{a}} \text { Ordem }\end{array}$ & $\begin{array}{l}\text { Cobertura Florestal Nativa } \\
\text { Florestas Plantadas }\end{array}$ \\
\hline \multirow{2}{*}{2} & \multirow{2}{*}{$\begin{array}{c}\text { Suave } \\
\text { Ondulado } \\
(3-8 \%)\end{array}$} & \multirow{2}{*}{---} & $\begin{array}{c}\text { Sequência } \\
\text { Vulcanossedimentar } \\
\text { proterozoica }\end{array}$ & \multirow{2}{*}{---} & \multirow{2}{*}{--- } & \multirow{2}{*}{$\begin{array}{l}\text { Mosaico de Vegetação } \\
\text { Campestre com Áreas } \\
\text { Agrícolas }\end{array}$} \\
\hline & & & $\begin{array}{c}\text { Complexos Gnaisse- } \\
\text { Migmatítico/ } \\
\text { Granulito } \\
\end{array}$ & & & \\
\hline 3 & $\begin{array}{l}\text { Ondulado } \\
(8-20 \%) \\
\end{array}$ & $\begin{array}{l}\text { Argissolo Vermelho } \\
\text { Amarelo }\end{array}$ & --- & --- & $\begin{array}{l}3^{\mathrm{a}} \text { Ordem/ } \\
4^{\mathrm{a}} \text { Ordem }\end{array}$ & $\begin{array}{l}\text { Pastagem Natural ou } \\
\text { Artificial }\end{array}$ \\
\hline \multirow[t]{2}{*}{4} & $\begin{array}{c}\text { Forte } \\
\text { Ondulado } \\
(20-45 \%) \\
\end{array}$ & \multirow[t]{2}{*}{---} & \multirow[t]{2}{*}{--- } & \multirow{2}{*}{$\begin{array}{l}1.086,26- \\
1.129,42\end{array}$} & \multirow[t]{2}{*}{$2^{\mathrm{a}}$ Ordem } & \multirow[t]{2}{*}{---} \\
\hline & $\begin{array}{c}\text { Montanhoso } \\
(45-67 \%)\end{array}$ & & & & & \\
\hline 5 & --- & $\begin{array}{l}\text { ArgissoloVermelho; } \\
\text { Neossolo Litólico; }\end{array}$ & $\begin{array}{c}\text { Cobertura cenozoica } \\
\text { detrito-laterítica }\end{array}$ & --- & $1^{\mathrm{a}}$ Ordem & $\begin{array}{c}\text { Edificações/Urbanização/Solo } \\
\text { Exposto }\end{array}$ \\
\hline
\end{tabular}

Table 4. Classes of fragility attributed to the factors considered for Capelinha, Minas Gerais, Brazil. 

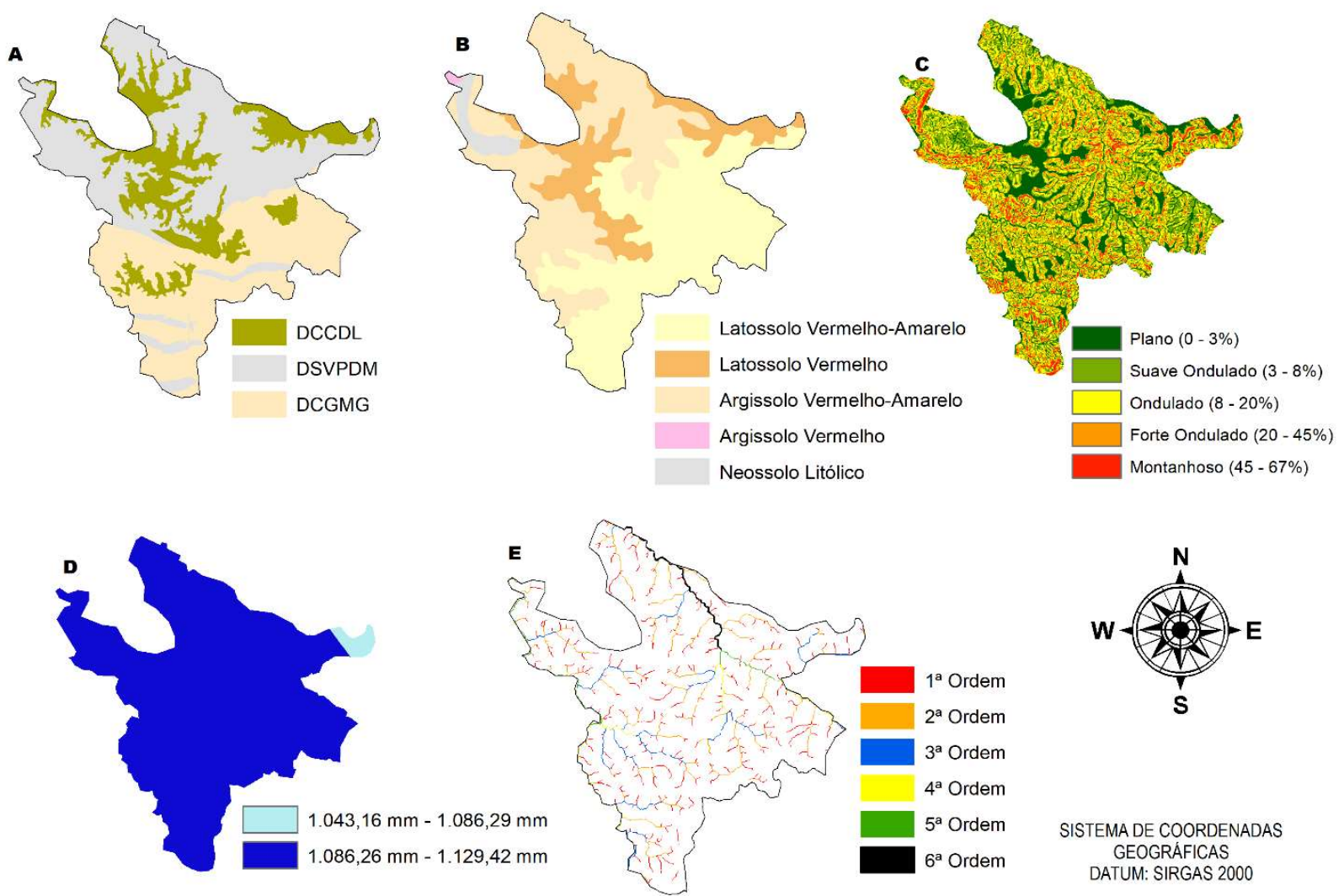

SISTEMA DE COORDENADAS

DATUM: SIRGAS 2000

Figura 2. Prancha com mapas multicritérios considerados na avaliação. (A) Domínios Geológicos (DCCDL: Domínio das Coberturas Cenozoicas Detrito-Lateríticas, DSVPDM: Domínio das Sequências Vulcanossedimentares Proterozoicas dobradas metamorfizadas em baixo e alto grau e DCGMG: Domínio dos Complexos Gnaisse-Migmatítico e Granulitos; (B) Classes de Solos; (C) Declividade do Terreno; (D) Pluviosidade e (E) Hierarquia de Drenagens.

Figure 2. Sketch with maps of the multicriteria considered in the evaluation. (A) Geological Domains (DCCDL: Domain of Cenozoic DebrisLateritic Covers, DSVPDM: Domain of Proterozoic Low and High metamorphosed Vulcanosedimentary Sequences and DCGMG: Domain of the Gneiss-Migmatite and Granulite Complexes; (B) Soils Classes; (C) Land Declivity; (D) Rainfall and (E) Drainage Hierarchy.

Quanto a Uso e Ocupação do Terreno, foram relacionadas as seis classes de diferentes tipos de uso e configuração espacial do terreno: pastagem natural ou artificial, mosaico de vegetação campestre com áreas agrícolas, solo exposto, cobertura florestal nativa, silvicultura e área artificial, em conformidade com França et al. (2018), em estudo confeccionado a partir da classificação de uso da terra do IBGE (2016). O Mapa de Uso e Ocupação do Terreno para o município de Capelinha é apresentado na Figura 3.

Em termos de fragilidade ambiental, seguiu-se a metodologia de Ross (1994), o qual analisa uso e ocupação do terreno como graus de proteção do mesmo. Nesse sentido, neste trabalho, considera-se como classe Baixa as áreas de cobertura florestal e florestas plantadas; Levemente Baixa, áreas caracterizadas como mosaico de vegetação campestre com áreas agrícolas; classe de fragilidade Média, áreas de pastagem natural ou artificial; e classe Extremamente Alta, áreas de edificações / urbanização / solo exposto.

3.1. Razão de Consistência AHP para a fragilidade ambiental da área em estudo

A partir da ponderação de todos os parâmetros utilizados no estudo, para geração da hierarquia de Importância e Razão de Consistência da análise, gerou-se uma tabela de comparação par a par (Tabela 5), e, posteriormente, outra tabela de níveis de importância dos fatores de análise (Tabela 6).

Tabela 5. Matriz de comparação par a par para geração dos níveis de importância.

Table 5. Peer-to-peer comparison matrix for generation of importance level.

\begin{tabular}{lcccccc}
\hline \multirow{2}{*}{$\begin{array}{c}\text { Matriz de Fatores de } \\
\text { Importância }\end{array}$} & $\begin{array}{c}\text { Uso e Ocupação } \\
\text { do Terreno }\end{array}$ & $\begin{array}{c}\text { Classes de } \\
\text { Solo }\end{array}$ & $\begin{array}{c}\text { Declividade } \\
\text { do Terreno }\end{array}$ & $\begin{array}{c}\text { Domínios } \\
\text { Geológicos }\end{array}$ & $\begin{array}{c}\text { Hierarquia } \\
\text { Fluvial }\end{array}$ & Pluviosidade \\
\hline Uso e Ocupação do Terreno & 1 & 2 & 2 & 3 & 2 & 3 \\
Classes de Solo & 0,5 & 1 & 0,5 & 2 & 0,5 & 0,5 \\
Declividade do Terreno & 0,5 & 2 & 1 & 3 & 2 & 3 \\
Domínios Geológicos & 0,33 & 0,5 & 0,33 & 1 & 0,5 & 0,33 \\
Hierarquia Fluvial & 0,5 & 2 & 0,5 & 2 & 1 & 0,5 \\
Pluviosidade & 0,5 & 3 & 2 & 3 & 2 & 1 \\
\hline
\end{tabular}




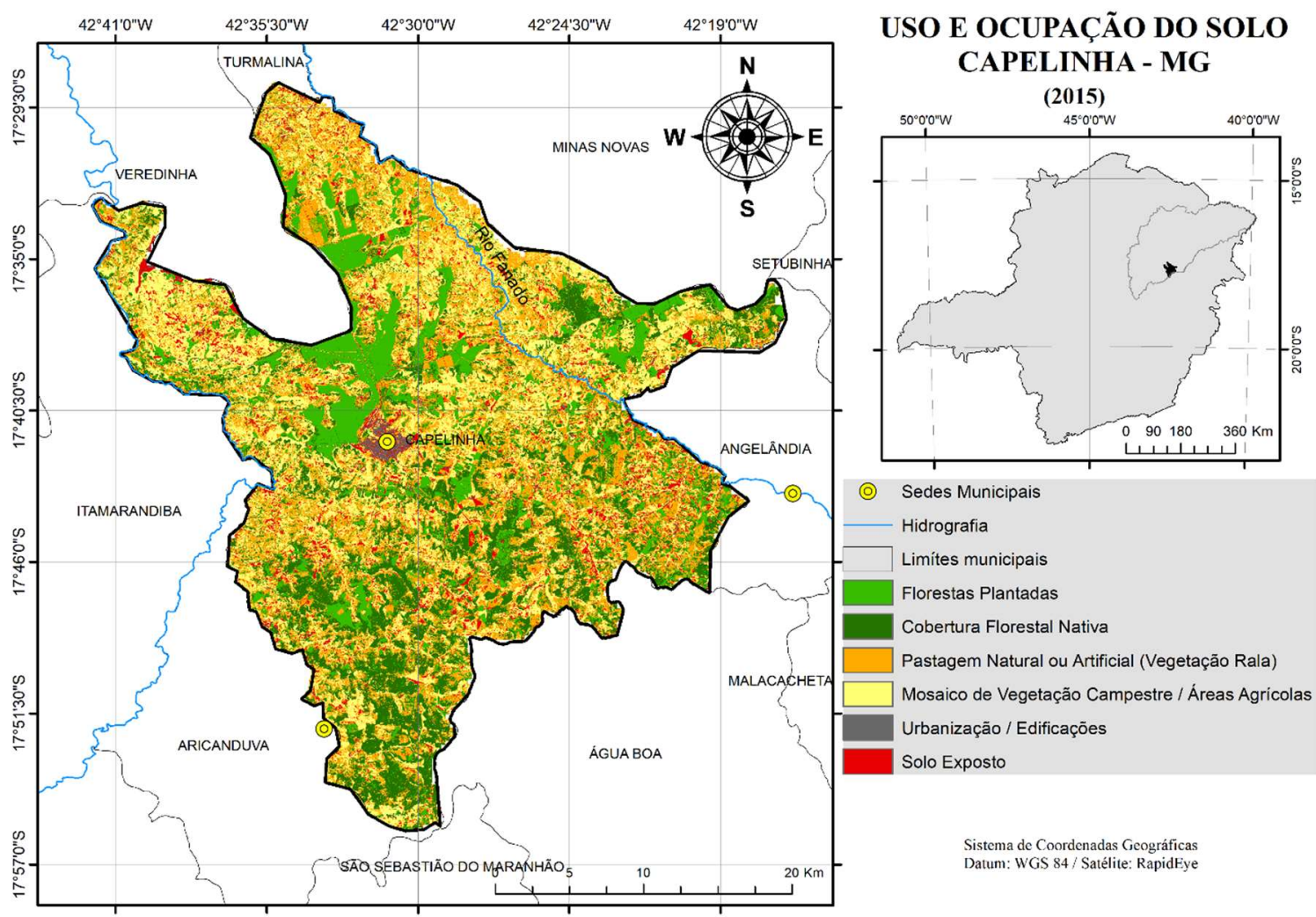

Figura 3. Mapa de uso e ocupação do terreno de Capelinha, Minas Gerais, Brasil. Figure 3. Land use and occupation map of Capelinha, Minas Gerais, Brazil.

Tabela 6. Níveis de importância dos fatores de análise. Table 6. Levels of importance of the analysis factors.

\begin{tabular}{lcc}
\hline \multicolumn{1}{c}{ Fatores } & Pesos finais & Porcentagem (\%) \\
\hline Uso e Ocupação do & 0,2719 & 27,2 \\
Declividade do Terreno & 0,2227 & 22,3 \\
Pluviosidade & 0,2205 & 22,1 \\
Hierarquia Fluvial & 0,1246 & 12,5 \\
Classes de Solo & 0,0983 & 9,8 \\
Domínios Geológicos & 0,0621 & 6,2 \\
\hline \multicolumn{1}{c}{ Total $(\Sigma)$} & 1,0 & 100 \\
\hline
\end{tabular}

Os níveis de importância para a matriz de comparação par a par foram definidos para este trabalho tendo por base o julgamento técnico de especialistas de distintas áreas de pesquisa (Geomorfologia, Geologia, Pedologia e Engenharia Florestal), para os fatores explicitados na Tabela 5.

Para a verificação da consistência dos dados, calculou-se o Índice de Consistência (IC), aplicando-se a equação (SAATY, 2005):

$$
\text { I. } C=\frac{\lambda \operatorname{Max}-n}{n-1} \therefore \frac{6,3887-6}{6-1}=I C=0,0777
$$

A fim de se verificar se o valor encontrado do Índice de Consistência (IC) é adequado, aplica-se a Equação (2), que identifica a Razão de Consistência (RC), a qual consiste na divisão entre o IC e o IR (Índice Randômico), verificado na tabela de Saaty (2005), de acordo com a dimensão da matriz (n). Nesse caso, $\mathrm{n}=5$, verificou-se um IR de 1,12, o que posteriormente foi aplicado à equação da RC (SAATY, 2005):

$$
\text { R.C }=\frac{I C}{I R} \therefore \frac{0,0777}{1,24}=\text { R.C }=0,0627
$$

A Razão de Consistência (RC) encontrada foi de 0,0627.

\subsection{Fragilidade Potencial}

De posse dos mapas finais referentes aos Planos de Informações (PI) avaliados para o município de Capelinha, Minas Gerais, realizou-se o cruzamento dessas informações para a obtenção da fragilidade potencial. Assim, a quantificação das áreas por classes encontra-se na Figura 4, que apresenta a espacialização de tais classes, compondo o Mapa Final de Fragilidade Potencial.

Pela figura 4, observa-se que a maior parte da área em estudo classifica-se como de fragilidade Levemente Baixa $\left(485,10 \mathrm{~km}^{2}\right)$. As menores áreas compõem classes Extremamente Alta $\left(8,32 \mathrm{~km}^{2}\right)$, seguidas pela Alta $\left(38,81 \mathrm{~km}^{2}\right)$. A fragilidade média aparece em 283,30 km², e a Baixa ocupa $111,79 \mathrm{~km}^{2}$. Fragilidades potenciais Baixa e Levemente Baixa compõem, juntas, $596 \mathrm{~km}^{2}$, e associam-se pela análise do Mapa de Declividade do Terreno (Figura 2C) a áreas planas ou suavemente onduladas. Grande parte dessas áreas correlaciona-se a feições no relevo denominadas chapadas, ocorrentes principalmente na porção centro-norte do município de Capelinha, recoberta, no Mapa de Domínios Geológicos, por Coberturas Detrito-Lateríticas Cenozoicas (Figura 2A).

\subsection{Fragilidade Emergente}

Após ter sido gerada a carta de fragilidade potencial, incluiu-se, na álgebra de mapas, o parâmetro de Uso e Ocupação do Terreno obtido por mapeamento em imagens RapidEye de 2015. Na Figura 5, é apresentado o mapa final de Fragilidade Emergente para o município, bem como a quantificação das áreas das classes da fragilidade emergente.

O peso final foi dado pelo Uso e Ocupação do Terreno, conforme a Tabela 6. Nesse sentido, a quantificação em área $\left(\mathrm{km}^{2}\right)$ para o município de Capelinha apresentou um aumento 
expressivo das classes Alta e Extremamente Alta (Figura 5), $283 \mathrm{~km}^{2}$ (fragilidade potencial) para $244 \mathrm{~km}^{2}$ (fragilidade que passam a ocupar áreas com cerca de 120 e $42 \mathrm{~km}^{2}$, emergente). respectivamente, em detrimento da classe Média, que passa de

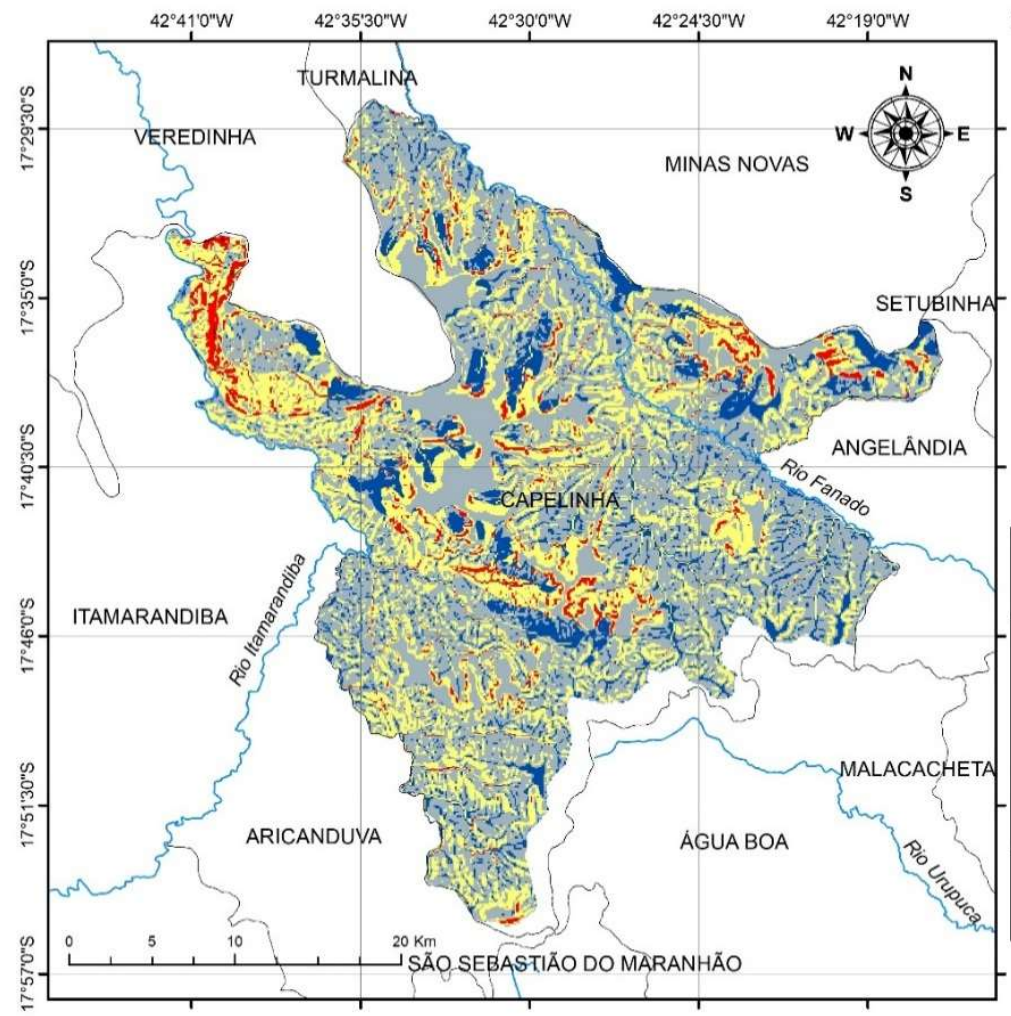

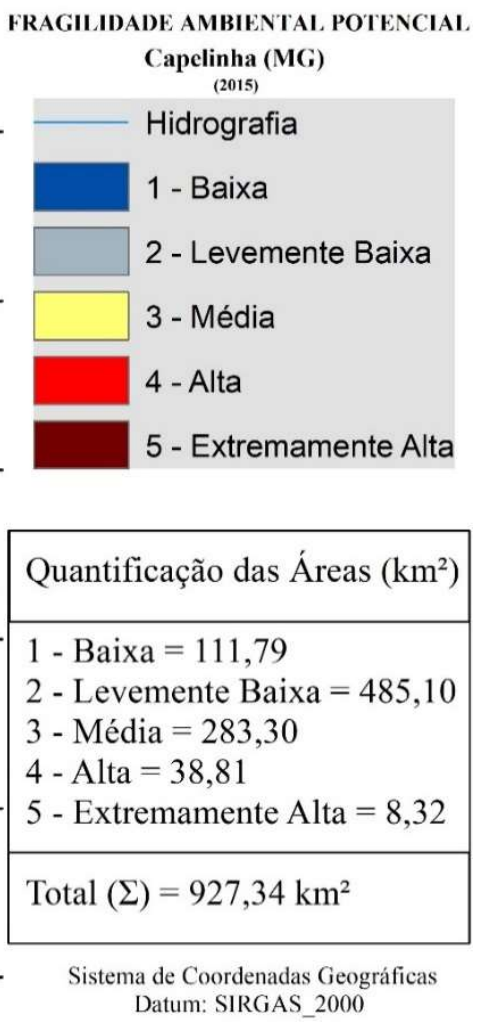

Figura 4. Mapa de Fragilidade Ambiental Potencial (FAP) de Capelinha, MG, com valores de área para cada classe.

Figure 4. Potential Environmental Fragility Map (PEF) of Capelinha, MG, with area values for each class.
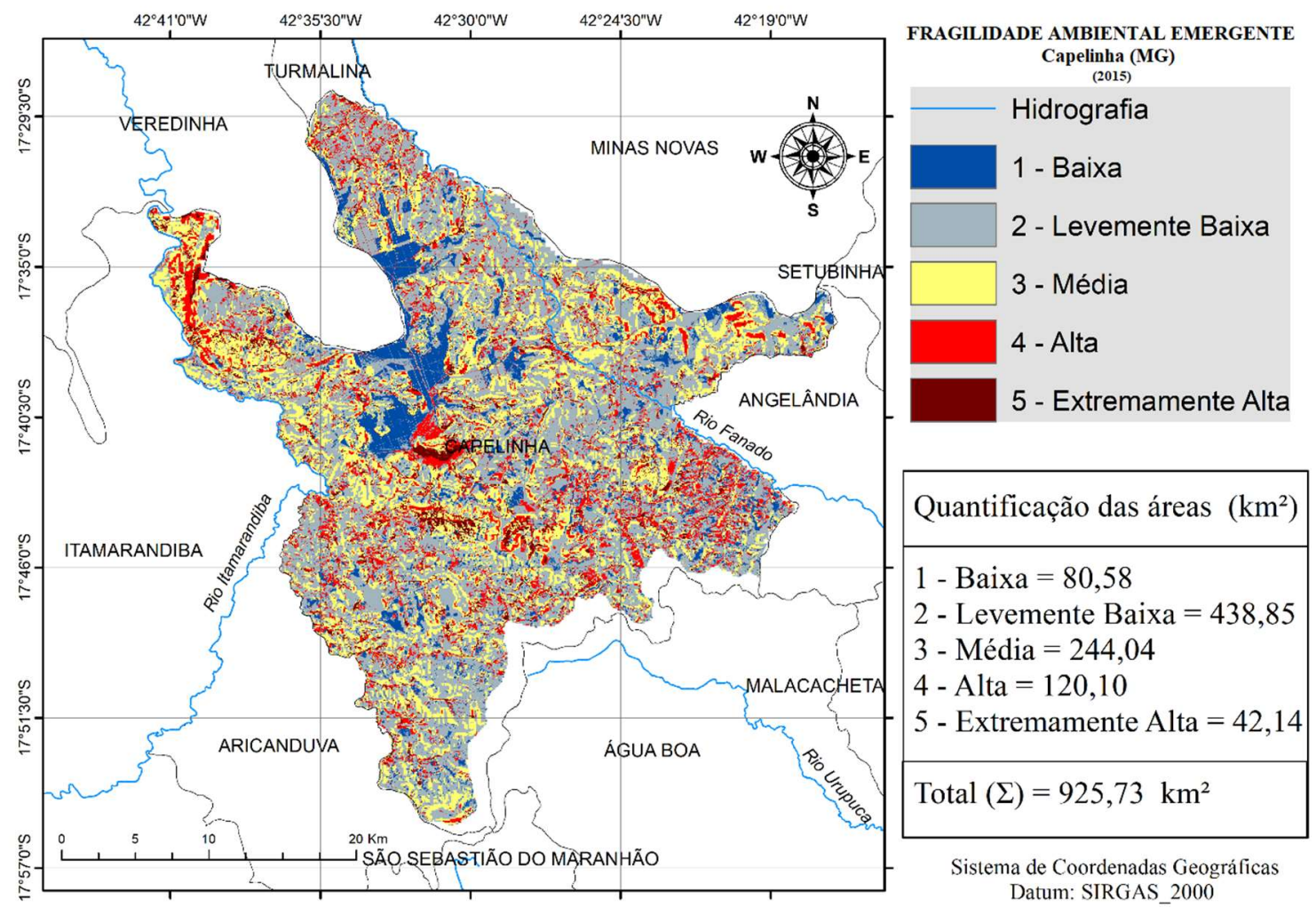

Figura 5. Mapa de Fragilidade Ambiental Emergente (FAE) de Capelinha, MG, com valores de área para cada classe.

Figure 5. Map of Emergent Environmental Fragility (EEF) of Capelinha, MG, with area values for each class. 


\section{DISCUSSÃO}

\subsection{Multicritérios}

Conforme observado na Tabela 4, as áreas com os maiores potenciais de fragilidade são aquelas com argissolo vermelho e neossolo litólico, e as menores fragilidades estão nas áreas com latossolo vermelho e vermelho-amarelo. Resultado semelhante foi encontrado por Fushita et al. (2012) em área de estudo com predominância de classe de baixa fragilidade que, associada à ocorrência de latossolos, se mostrou reconhecidamente permeável e resistente à erosão. A Figura 4 apresenta a disposição dos solos na área do município.

É importante destacar que, para o mapeamento da fragilidade potencial e emergente, a declividade apresenta-se como um importante fator de análise, tendo em vista que os processos erosivos que venham a ocorrer na região podem ser acelerados conforme o grau de inclinação.

Portanto, a avaliação da declividade média de uma região é relevante no planejamento, tanto para o cumprimento da legislação, quanto para a garantia da eficiência das intervenções do homem no meio. Além disso, a declividade possui importante papel na distribuição da água entre o escoamento superficial e subterrâneo, dentre outros processos.

A soma de fatores como ausência de cobertura vegetal, presença de determinada classe de solo e intensidade de chuvas, dentre outros, associada à maior declividade, conduzirá a uma maior velocidade de escoamento e menor quantidade de água armazenada no solo e, consequentemente, resultará em enchentes mais pronunciadas, sujeitando a bacia à degradação (TONELLO et al., 2006). Lepsch (2002) destaca, ainda, que a declividade do terreno influencia na concentração, na dispersão e na velocidade de enxurradas e, em consequência, no maior ou menor arrastamento superficial das partículas de solo.

O grau de coesão das rochas representa a intensidade da ligação entre os minerais ou partículas que as constituem, e é a informação básica da Geologia, a ser integrada a partir da ecodinâmica. Nesse sentido, em rochas pouco coesas devem prevalecer os processos erosivos, modificadores das formas de relevo (morfogênese). Já em rochas bastante coesas prevalecem os processos de intemperismo e de formação de solos (pedogênese) (CREPANI et al., 2001).

Quanto a pluviosidade, Panagos et al. (2017) destacam que o principal fator erosivo em regiões tropicais ou subtropicais úmidas é a ação das chuvas. Os autores geraram um mapa de erosividade global, de modo a verificar as áreas em todo o planeta onde a chuva tem maior potencial de causar movimentação do solo, e constataram que elas se concentram na faixa tropical do planeta, especialmente nos países da América do Sul (>3.700 MJ mm ha ${ }^{-1} \mathrm{~h}^{-1}$ ano $\left.{ }^{-1}\right)$, sendo a maior parte dessas áreas localizada no Brasil $(>7.000 \mathrm{MJ} \mathrm{mm}$ ha ${ }^{-1} \mathrm{~h}^{-1}$ ano ${ }^{-1}$ ).

Em termos de hierarquia fluvial, Vitte; Villela Filho (2006), pautados pelos conceitos de Christofoletti (1980), destacam que é possível dizer que quanto maior a participação percentual de canais de primeira ordem, maior deverá ser a fragilidade potencial do relevo, pois a drenagem de primeira ordem indica uma maior instabilidade do ambiente. Estes representam os setores de desenvolvimento das bacias de drenagem, locais onde processos morfodinâmicos, associados à dissecação do relevo, são mais intensos. Além disso, a instalação da drenagem de primeira ordem, e seu desenvolvimento, está relacionada às variações do perfil de equilíbrio do canal principal, ou mesmo às influências litoestruturais, estruturais e às variações climáticas ao longo do Quarternário.

\subsection{Analytic Hierarch Process (AHP)}

Quanto a consistência da matriz matemática AHP, a Razão de Consistência (RC) encontrada foi de 0,0627 , logo, dentro dos limites aceitáveis $(0,1)$ determinados por Saaty (1990), demonstrando que as comparações realizadas foram coerentes e geraram resultados confiáveis. A razão confirma, ainda, que a matriz foi preenchida de maneira aleatória, logo, consistente, não necessitando de reestruturação.

\subsection{Fragilidade Potencial}

A fragilidade Levemente Baixa é, também, comumente observada na porção centro-sul do município, em domínio geológico de rochas gnáissicas, onde o relevo é fortemente ondulado, mas com predominância de latossolos.

A declividade do terreno é um dos fatores de maior peso dentre os analisados para fragilidade potencial, condicionando em toda área do município a classe de fragilidade Média, representada no mapa pela coloração amarela (Figura 4). Na porção centro-norte do município, às margens de áreas mais planas e/ou chapadas, ocorrem drenagens de primeira ordem, indicativas de dissecação do relevo, as quais possuem peso considerável na mudança da classe de fragilidade. Na porção centro-sul, por sua vez, onde há dominância de relevo fortemente montanhoso, há predominância da classe de Média fragilidade.

As classes de fragilidade potencial Alta e Extremamente Alta somam 47,13 $\mathrm{km}^{2}$ e encontram-se muito condicionadas a uma declividade fortemente montanhosa (Figura 2C), a hierarquias de $1^{\mathrm{a}}$ e $2^{\mathrm{a}}$ ordens (Figura $2 \mathrm{E}$ ) e a presença de argissolos. São mais expressivas em vertentes que contornam as chapadas na porção centro-norte, assim como no extremo noroeste do município (Figura 4), porção com ocorrência significativa de neossolos litólicos, onde, além da classe Alta, há áreas pontuais de classe Extremamente Alta (Tabela 4).

\subsection{Fragilidade Emergente}

No que concerne às classes Alta e Extremamente Alta, nota-se uma ampla distribuição pelo território do município, com concentração na sede municipal de Capelinha. Entretanto, fora do ambiente urbano, há áreas de concentração de tais classes como, por exemplo, na porção centro-leste e em porções do extremo oeste (Figura 5). Pelo Mapa de Uso e Ocupação do Terreno, em tais áreas há predominância de solo exposto, mosaico de vegetação campestre/áreas agrícolas e, subordinadamente, florestas plantadas (Figura 3). Ademais, o aumento da fragilidade potencial vinculado à classe de solo exposto pode estar relacionado às queimadas, prática usual na região do Alto Jequitinhonha, vinculada à formação de novas pastagens (normalmente por gramíneas exóticas). Entretanto, tal prática pode ser responsável por proliferação de espécies como a samambaia (Pteridium aquilinum).

Uma diferença marcante é observada nas áreas planas (chapadas), as quais estão classificadas como de Baixa ou Levemente Baixa fragilidade emergente. Tal análise é necessária, uma vez que cerca de $12 \%$, ou $117,02 \mathrm{~km}^{2}$, do território de Capelinha é destinado ao uso e ocupação do terreno por florestas plantadas (FRANÇA et al., 2018), especialmente pela espécie Eucalyptus spp. Portanto, tal uso é intensivo e deveria apresentar um aumento, e não diminuição, de classe de fragilidade.

Uma explicação para esse fato deve-se à análise de Ross 
(1994), o qual afirma que florestas plantadas (ou cultivadas) acabam por apresentar alto grau de proteção de um terreno no que concerne a sua cobertura florestal. Nesse sentido, quando se realiza a ponderação ao longo da metodologia aplicada, a área tende a uma Baixa fragilidade emergente.

Entretanto, dado o fato de tais florestas ocuparem extensas áreas do Alto e Médio Vale do Jequitinhonha, ocasionando baixa diversidade em áreas ocupadas, assim como necessitarem de aplicações sucessivas de defensivos e fertilizantes, além de maior demanda por água para seu crescimento (se comparadas à cobertura florestal nativa), são inúmeros os impactos negativos a elas vinculados. Nesse sentido, recomendam-se estudos futuros em direção de um aprimoramento da metodologia aqui empregada, utilizando-se, por exemplo, imagens para análise temporal que evidenciem todas as etapas vinculadas ao reflorestamento, ou seja, do plantio ao corte, uma vez que, ao longo dessas etapas, o grau de exposição do terreno se torna variável.

\section{CONCLUSÕES}

Quanto à análise da fragilidade ambiental potencial, podese constatar que a maior parte do município apresenta fragilidade de Levemente Baixa à Média. Já a análise da fragilidade ambiental emergente enquadra-se majoritariamente nas classes Levemente Baixa e Alta, o que não descaracteriza a atenção as áreas de fragilidades Alta e Extremamente Alta.

A técnica de análise por múltiplos critérios e pelo método AHP mostrou-se eficiente na hierarquização da importância dos critérios para geração das cartas de fragilidade ambiental da área de estudo, com maior fidedignidade.

O uso da modelagem de dados não elimina a necessidade de processos de validação mais precisos e robustos, bem como de avanços nas avaliações e nos diagnósticos de campo, sendo recomendado o aprofundamento metodológico neste sentido. Uma vez que o modelo utilizado é um vislumbre da possível condição de fragilidade ambiental de Capelinha (MG), e não a realidade em si.

\section{AGRADECIMENTOS}

O presente trabalho foi realizado com apoio da Coordenação de Aperfeiçoamento de Pessoal de Nível Superior - Brasil (CAPES) - Código de Financiamento 001. LCJF agradece ainda à UFVJM e Universidade do Porto pela complementação sanduíche. Agradecimentos especiais aos Prof. Dr. Jurandyr Ross (USP), Prof. Dr. Allaoua Saadi (UFMG) e Prof. João Honrado Pradinho (Universidade do Porto) pelas contribuições científicas.

\section{REFERÊNCIAS}

CHRISTOFOLETTI, A. Geomorfologia. 2. ed. São Paulo: Edgard Blücher, 1980. 188 p.

CPRM. Serviço Geológico do Brasil. Atlas pluviométrico do Brasil. 2016. Disponível em: $<$ http://www.cprm.gov.br/publique/cgi/cgilua.exe/sys/star t.htm?infoid=1351\&sid=9>. Acesso em: 10 ago. 2016.

CREPANI, E.; MEDEIROS, J. S. de; FILHO, P. H.; FLORENZANO, T. G.; DUARTE, V.; BARBOSA, C. C. F. Sensoriamento remoto e geoprocessamento aplicados ao zoneamento ecológico-econômico e ao ordenamento territorial. São José dos Campos: Instituto Nacional de Pesquisas Espaciais - INPE, 2001. 124 p.
EMBRAPA_EMPRESA BRASILEIRA DE PESQUISA AGROPECUÁRIA. Serviço Nacional de Levantamento e Conservação de Solos. Rio de Janeiro: Súmula/SNLCS, 1979. 87 p. (Reunião Técnica de Levantamento de Solos, 10)

EMBRAPA_EMPRESA BRASILEIRA DE PESQUISA AGROPECUÁRIA. O novo mapa de solos do Brasil: legenda atualizada. Rio de Janeiro: IBGE / Embrapa Solos, 2011. 67p.

ESRI_ENVIRONMENTAL SYSTEMS RESEARCH INSTITUTE. ArcGIS 10.0: GIS by ESRI. ESRI, 2013.

FEAM - Fundação Estadual do Meio Ambiente. Mapa de solos do Estado de Minas Gerais. Belo Horizonte: UFV - CETEC - UFLA, 2010. Disponível em: $<$ http://www.feam.br/noticias/1/949-mapas-de-solo-doestado-de-minas-gerais> Acesso em: 10 jun. 2018.

FRANÇA, L. C. J.; PIUZANA, D.; MORAIS, M. S. Sistema de Informações Geográficas (SIG) na análise de uso do terreno, cobertura vegetal e ordenamento territorial no município de Capelinha, Minas Gerais. In: PEREIRA, I. M. (Org.). Invasão Biológica em áreas de Mata Atlântica: os desafios para conservação, controle e restauração florestal. 2018.

FUSHITA, A. T.; BORTOLIN, L. H. G. C.; ARANTES, E. M.; MOREIRA, M. A. A.; CANÇADO, C. J.; LORANDI, R. Fragilidade Ambiental Associada ao Risco Potencial de Erosão de Uma Área da Região Geoeconômica Médio Mogi Guaçu Superior (SP). Revista Brasileira de Cartografia, Monte Carmelo, v. 63, n.4, p.477-488, 2012. IBGE INSTITUTO BRASILEIRO DE GEOGRAFIA E ESTATÍSTICA. DIRETORIA DE GEOCIÊNCIAS. Diagnóstico ambiental da bacia do rio Jequitinhonha: diretrizes gerais para a ordenação territorial. Salvador: IBGE, 1997.

IBGE_INSTITUTO BRASILEIRO DE GEOGRAFIA E ESTATÍSTICA. DIRETORIA DE GEOCIÊNCIAS, COORDENAÇÃO DE RECURSOS NATURAIS E ESTUDOS AMBIENTAIS. Mudanças de Cobertura e Uso da Terra 2000 - 2010 - 2012 - 2014. Rio de Janeiro: IBGE, 2016.

LEPSCH, I. F. Formação e Conservação dos Solos. 2. ed. São Paulo: Oficina de textos, 2010. 216 p.

LOPES, E.R.N.; SALES, J.C.A.; AMORIM, A, T.; ALBUQUERQUE FILHO, J.L.; LOURENÇO, R. W. Losses on the Atlantic mata vegetation induced by land use changes. Cerne, Lavras, v. 24, n. 2, p. 121-132, 2018. DOI: https://dx.doi.org/10.1590/01047760201824022512

LUEDELING, E.; SIEBERT, S.; BUERKERT, A. Filling the voids in the SRTM elevation model - A TIN-based delta surface approach. ISPRS Journal of Photogrammetry and Remote Sensing, Amsterdam, v. 62, n. 4, p. 283-294, 2007.

DOI: https://dx.doi.org/10.1016/j.isprsjprs.2007.05.004

MANFRÉ, L. A.; SILVA, A.M.; URBAN, R.C.; RODGERS, J. Environmental fragility evaluation and guidelines for environmental zoning: a study case on Ibiuna (the Southeastern Brazilian region). Environmental Earth Sciences, Heidelberg, v. 69, n. 3, p. 947-957, 2013. DOI: https://dx.doi.org/10.1007/s12665-012-1979-2

MELO, F. P.; MELO E SOUSA, R.; ROSS, J. L. S. Modelagem de geoformas para mitigação do risco geoambiental em Garanhus-PE. Acta Geográfica, Boa Vista, v. 10, n. 22, p. 87-115, 2016. 
MELO, F. P.; GOIS, D.V.; SANTOS, C. A.; MELO E SOUSA, R.; GUERRA, A. J. T. Estruturação de modelo de risco de degradação ambiental aplicado ao Município de Pacatuba - SE. Caderno de Geografia, Belo Horizonte, v. 28, n. 48, 2018. DOI: https://dx.doi.org/10.5752/P.23182962.2018v28n54p674-685

MIRANDA, E. E.(Coord.). Brasil em Relevo. Campinas: Embrapa Monitoramento por Satélite, 2005. Disponível em: <http://www.relevobr.cnpm.embrapa.br >. Acesso em: 14 Jun. 2017.

OLIVEIRA, P. T.S.; SOBRINHO, T.A.; STEFFEN, J. L.; RODRIGUES, D. B. B. Caracterização morfométrica de bacias hidrográficas através de dados SRTM. Rev. Bras. de Eng. Agrícola e Ambiental, Campina Grande, v. 14, n. 8, p. 819-825, 2010. DOI: http://dx.doi.org/10.1590/S1415-43662010000800005

PANAGOS, P.; BORRELLI, P.; MEUSBURGER, K,; YU, B.; KLIK, A.; LIM, K. J.; YANG, J. E.; NI, J.; MIAO, C.; CHATTOPADHYAY, N.; SADEGHI, S. H.; HAZBAVI, Z.; ZABIHI, M.; LARIONOV, G. A.; KRASNOV, S. F.; GOROBETS, A. V.; LEVI, Y.; ERPUL, G.; BIRKEL, C.; HOYOS, N.; NAIPAL, V.; OLIVEIRA, P. T. S.; BONILLA, C. A.; MEDDI, M.; NEL, W.; DASHTI, H. A.; BONI, M.; DIODATO, N.; OOST, K. V.; NEARING, M.; BALLABIO, C. Global rainfall erosivity assessment based on high-temporal resolution rainfall records. Scientific Reports - Nature. v. 7, n. 1, p. 4175, 2017. DOI: http://dx.doi.org/10.1038/s41598-017-04282-8

QUARTAROLI, C. F.; ARAÚJO, L. S.; GARÇON, E. A. M. Carta de vulnerabilidade natural à perda de solo do Estado do Maranhão. 21. ed. Campinas: Embrapa Monitoramento por Satélite, 2013. 44p.

ROSS, J. L. S. Landforms and environmental planning: Potentialities and Fragilities. Revista do Departamento de Geografia, vol. esp., p.38-51, 2012. DOI: https://dx.doi.org/10.7154/RDG.2012.0112.0003

SAATY, T. L. How to make a decision: The Analytic Hierarchy Process. European Journal of Operational Research, Amsterdam, v. 48, n. 1-5, p. 9-26, 1990. DOI: https://dx.doi.org/10.1016/0377-2217(90)90057-I
SAATY, T. L. Theory and Applications of the Analytic Network Process: Decision Making with Benefits, Opportunities, Costs, and Risks. Pittsburgh: RWS Publications, 2005. $352 \mathrm{p}$.

SAATY, T.S. Decision making with the analytic hierarchy process. International Journal of Services Sciences, v. 1, n. 1, p. 83-98, 2008.

SANTOS, L. F.; CRUZ, R. B. C. O uso do método AHP na tomada de decisão para seleção de lajes de edifícios comerciais. Engenharia, Estudo e Pesquisa, ABPE, Rio de Janeiro, v. 13, n. 1, p 39-52, 2013.

STRAHLER, A. N. Hypsometric analysis of erosional topography. Bulletin of the Geological Society of America, Washington v. 63, n. 11, p. 111-1141, 1952. DOI: $\quad$ https://dx.doi.org/10.1130/00167606(1952)63[1117:HAAOET]2.0.CO;2

TAMANINI, M. S. A. Diagnóstico físico-ambiental para determinação da fragilidade potencial e emergente da Bacia do Baixo Curso do Rio Passaúna em Araucária PR. 2008. 105f. Dissertação (Mestrado em Geografia), Universidade Federal do Paraná, Curitiba, 2008.

TONELLO, K. C.; DIAS, H. C. T.; SOUZA, A. L.; RIBEIRO, C. A. A. S.; LEITE, F. P. Morfometria da bacia hidrográfica da cachoeira das Pombas, Guanhães - MG. Revista Árvore, Viçosa, v. 30, n. 5, p. 849-857, 2006. DOI: http://dx.doi.org/10.1590/S010067622006000500019

TRICART, J. Ecodinâmica. Rio de Janeiro: IBGE, Secretaria de Planejamento da Presidência da República, 1977.

VALLE, I. C.; FRANCELINO, M. R.; PINHEIRO, H. S. K. Mapeamento da fragilidade ambiental na Bacia do Rio Aldeia Velha, RJ. Floram, Seropédica, v. 23, n. 2, p. 295 308, 2016. DOI: http://dx.doi.org/10.1590/21798087.107714

VITTE, A. C.; VILELA FILHO, L. R. A urbanização, a fragilidade potencial do relevo e a produção do risco na bacia hidrográfica do Córrego Proença, município de Campinas, Brasil. Territorium: Rev. Portuguesa de riscos, prevenção e segurança, n. 13, p. 105-114, 2006.

XIE, H.; HE, Y.; ZHANG, N.; LU, H.; Spatiotemporal changes and fragmentation of forestland in Jiangxi Province, China. Journal of Forest Economics, n.29, p.413 , 2017.

DOI: https://dx.doi.org/10.1016/j.jfe.2017.08.004 